\title{
NAKED BARLEY INFLUENCE ON WHEAT BREAD QUALITY
}

\author{
Vita Sterna $^{1 *}$, Daiga Kunkulberga ${ }^{2}$, Evita Straumite ${ }^{2}$, Katrina Bernande ${ }^{1}$ \\ $1^{*}$ Department of Crop Selections and Agroecology, Institute of Agricultural Resources and Economics, Dizzemes, \\ Dizstende, Libagu parish, Talsu district, Latvia, e-mail: vita.sterna@arei.lv \\ ${ }^{2}$ Department of Food Technology, Faculty of Food Technology, Latvia University of Life Sciences and Technologies, \\ Rigas iela 22, Jelgava, Latvia
}

\begin{abstract}
Naked barley is a rich source of dietary fibre, non-starch polysaccharides, especially $\beta$-glucans and other functional ingredients. Therefore, there is a growing interest to include naked barley in products to increase their nutritional value. Barley is not popular for bakery products because its poor baking properties. High barley amount leads to decrease in bread loaf volume, storage time and consumer acceptability. Since it is known that using sourdough fermentation could be a possibility to obtain more acceptable products with higher nutrition value, producers interest to include barley flour in bread making increased. Therefore the aim of research was to evaluate nutritional characteristics, overall acceptability and storage possibility of bread enriched with naked barley grains or flour. Bread from $100 \%$ wheat flour type 812 was used as a control. There were prepared 7 samples of bread, where wheat bread was enriched with flour or grain of naked barley variety 'Kornelija' in the amount of 30 or $40 \%$ from total flour amount. Panellists were asked to evaluate intensity of bread sensory attributes - colour, aroma, porosity, hardness and sour taste - using 7-point unstructured line scale. Moisture and hardness of breads were evaluated after 24, 60 and $72 \mathrm{~h}$ of storage. Finally, bread samples enriched with barley grains had higher volume and porosity and lower hardness than samples enriched with barley flour. Samples enriched with barley flour prepared using sourdough method had sour taste and higher hardness. It was concluded, that all samples have maintained quality after $72 \mathrm{~h}$ of storage.
\end{abstract}

Keywords: naked barley, dietary fibre, $\beta$-glucans, sensory properties, wheat bread

\section{Introduction}

Increased interest in barley as a human food ingredient has been results from studies which have shown barley as an excellent source of dietary fibre, in particular, $\beta$-glucans (Arendt, Zannini, 2013; Baik, Ullrich, 2008). Including of barley grains in human nutrition is particularly valuable for diabetic patients and humans of risk group because its ability to lower glycemic index (Meija et al., 2019; Fulgoni et al., 2015; Jenkins et al., 2002). Barley (Hordeum vulgare L.) grain with high $\beta$-glucan content in the soluble dietary fibre fraction may be useful as a specialty crop for human food (Guler, 2003; Kalra, Jood, 2000).

Naked barley cultivars compared to hulled have increased nutritional value, especially content of protein, $\beta$-glucans and soluble dietary fibre and are free from the pales (Sterna et al., 2017; Baik, Ullrich, 2008) therefore it could be excellent raw material for functional food production.

One of main products used in daily diet is bread, unfortunately, barley is not popular for bakery products due to its poor baking properties and lower sensory acceptance of the products (Pejcz et al., 2016; Skendi et al., 2010; Jacobs et al., 2008), it does not contain gluten, which is necessary in bread making process. Bread producers are increasingly returning to simple raw materials and older technologies. Old processes, such as fermentation, are perceived as natural, and easier to understand than modern processes. The use of sourdough in the baking technology has been established as a traditional and potential process worldwide. Most of the positive effects on the texture and shelf life of the bread attributed to sourdough fermentation are caused by the produced metabolites (Su et al., 2019; Arendt et al., 2007). It has been demonstrated that sourdough improved the dough texture and bread quality of breads containing whole grain barley due to softening effect on bran particles during fermentation (Rieder et al., 2012) and increased arabinoxylans solubility (Pejcz et al., 2016; Gänzle 2014). The incorporation of naked barley in wheat bread and using different bread production methods strongly affects the quality of bread and is a possibility to increase bread nutritional value. Therefore, the aim of research was to evaluate nutritional characteristics, overall acceptability and storage possibility of bread enriched with naked barley grains or flour.

\section{Materials and Methods \\ Raw materials}

Grains and whole flour of a new naked barley variety 'Kornelija' (Stende, Latvia) characterised by high protein and $\beta$-glucans content and wheat flour Type 812 (Ltd Rigas Dzirnavnieks, Latvia) were used as main the raw materials. The chemical composition of raw material - naked barley grains of variety 'Kornelija' and wheat flour is summarised in the Table 1.

Table 1

Chemical composition of raw materials

\begin{tabular}{lcc}
\hline $\begin{array}{l}\text { Nutrients, } \\
\text { g per 100 g }\end{array}$ & $\begin{array}{c}\text { Naked barley } \\
\text { grain }\end{array}$ & $\begin{array}{c}\text { Wheat flour } \\
\text { Type 812 }\end{array}$ \\
\hline Protein & 20.80 & 13.40 \\
Fat & 2.11 & 1.30 \\
Ash & 2.63 & 0.70 \\
Starch & 47.90 & 66.0 \\
$\beta$-glucans & 6.15 & 0.60 \\
\hline
\end{tabular}

\section{Dough formulations and bread making}

Bread was made using different methods: direct method was used for a control - wheat bread (sample C) and 
samples D30 and D40, where wheat flour was replaced with barley flour as showed in Table 2. For samples G30 and G40 wheat flour was replaced with $300 \mathrm{~g}$ and $400 \mathrm{~g}$ soaked barley grain, respectively.

The added sourdough used in samples S30 and S40 was made from barley flour using Böcker (Germany) sourdough starter. Böcker sourdough starter work for all sourdough fermentation and contain the valuable lactic acid bacteria culture Lactobacillus sanfranciscensis. Additional ingredients for all bread recipes were $30 \mathrm{~g}$ sugar, $30 \mathrm{~g}$ salt and $30 \mathrm{~g}$ fresh baker's yeast.

Table 2

\section{Dough composition}

\begin{tabular}{lcccc}
\hline & \multicolumn{4}{c}{ Ingredients, g } \\
\cline { 2 - 5 } Sample & $\begin{array}{c}\text { Wheat } \\
\text { flour } \\
\text { type } \\
\mathbf{8 1 2}\end{array}$ & $\begin{array}{c}\text { Naked } \\
\text { barley } \\
\text { flour }\end{array}$ & $\begin{array}{c}\text { Naked } \\
\text { barley } \\
\text { grains }\end{array}$ & Water \\
\hline C & 1000 & - & - & 705 \\
D30 & 700 & 300 & - & 700 \\
D40 & 600 & 400 & - & 695 \\
G30 & 700 & - & 300 & 690 \\
G40 & 600 & - & 400 & 690 \\
S30 & 700 & $150^{1} / 150^{2}$ & - & 690 \\
S40 & 600 & $200^{1} / 200^{2}$ & - & 670 \\
\hline
\end{tabular}

1 - naked barley flour in sourdough,

2 - naked barley flour in dough.

C $-100 \%$ wheat bread; D30 - 30\% naked barley flour; D40 - 40\% naked barley flour; G30 - 30\% naked barley grains; G40 - 40\% naked barley grains; S30 - 30\% naked barley flour in sourdough; S40 - 40\% naked barley flour in sourdough.

The dough was mixed by means of a Varimixer Bear AR10 (Ltd Wodschow \& Co., Denmark) mixer for 7 minutes ( 3 minutes at a speed of $1 ; 4$ minutes at a speed of 2). The fermentation duration was 10 minutes at a room temperature $22 \pm 2{ }^{\circ} \mathrm{C}$ temperature. Then the dough was divided into pieces of $400 \pm 5 \mathrm{~g}$, placed into a container $(150 \times 70 \times 100 \mathrm{~mm}$ in size $)$ and fermented for 40 minutes at a $35 \pm 3{ }^{\circ} \mathrm{C}$ temperature. The bread was baked in convective oven Sveba Dahlen S8 for 30 minutes at a $200 \pm 10{ }^{\circ} \mathrm{C}$ temperature, with steam for first 3 seconds. The bread baking experiments were repeated twice.

After cooling, the bread samples were packaged in the polyethylene bags and stored at room temperature $\left(20 \pm 2{ }^{\circ} \mathrm{C}\right)$ for 5 days.

\section{Determination of loaf volume}

Loaf volume was measured by small seeds displacement method (Al-Saleh, Brennan, 2012). A container was used to measure the volume using rapeseeds. Seeds were poured into container of known volume until the bottom was covered. The loaf was placed inside the container which was then filled to the top with more seeds. The extra rapeseeds, which equal the loaf volume, were measured in a graduated cylinder. Samples were measured in triplicate, and the average data was recorded.

\section{Determination of weight los}

Weight loss (WL) was calculated based on the dough weight before baking and after baking. The weight loss $(\%)$ of the test bread samples was calculated using the following equation (1):

$$
\text { WL }(\%)=\frac{\mathrm{W}_{\text {dough }}-\mathrm{W}_{\text {hot bread }}}{\mathrm{W}_{\text {hot bread }}} \times 100
$$

where:

$\mathrm{W}_{\text {dough }}$ - weight of dough, $\mathrm{g}$;

$\mathrm{W}_{\text {hot bread }}$ - weight of bread after baking, $\mathrm{g}$.

\section{Bread moisture content determination}

Moisture content of breadcrumb was determined using air-oven (Memmert $\mathrm{GmbH}$, Germany) according AACC method 44-15.02 $24 \mathrm{~h}, 72 \mathrm{~h}$ and $96 \mathrm{~h}$ after baking.

\section{Determination of bread hardness during storage}

Hardness (N) of samples' breadcrumb was tested $24 \mathrm{~h}$, $72 \mathrm{~h}$ and $96 \mathrm{~h}$ after baking using Texture Analyser TA.HD.plus (Stable Micro Systems, UK) according to modified AACC method 74-09.01.

\section{Calculation of nutritional and energy values}

Nutrition and energy values were calculated using a specific Excel spreadsheet according Regulation (EU). No 1169/2011 of the European Parliament and of the Council of 25 October 2011 on the provision of food information to consumers.

\section{Sensory evaluation}

Wheat bread with naked barley flour and grain was evaluated by 39 panellists, with an average age of 38 years. A 7-point unstructured line scale was used for rating bread sensory attributes - colour, aroma, porosity, hardness and sour taste - intensity. Samples for panellists were assigned 3-digit codes and presented in a Williams' Latin Square design. Warm black tea was used as palate cleansers between samples. The format of the evaluation sheet, data collection and interpretation of data were processed with FIZZ Aquistion Ver.2.51 software (Biosystemes, France).

\section{Data statistical analysis}

Statistical data analysis was performed using SPSS 17.0. Sensory evaluation data were analysed by ANOVA using Fisher's least significant difference test (LSD) with a significance level of $95 \%(\mathrm{p}<0.05)$.

\section{Results and Discussion}

Bread loaf volume is an important attribute of baked product quality as increased loaf volume leads to softer crumb, improved eating quality and higher consumer preference. High loaf volume of bread can be achieved by several parameters including flour quality, different ingredients, the baking process and addition of enzymes. Results of loaf volume measurements confirmed that high barley concentration led to decrease in loaf volume (Pejcz et al., 2016; Jacobs et al., 2008). Volume of samples D30 with 30\% naked barley flour was determined higher $-811 \pm 11 \mathrm{~mL}$ than volume of samples D40 - 711 $\pm 9 \mathrm{~mL}$ (Table 3 and Figure 1). 


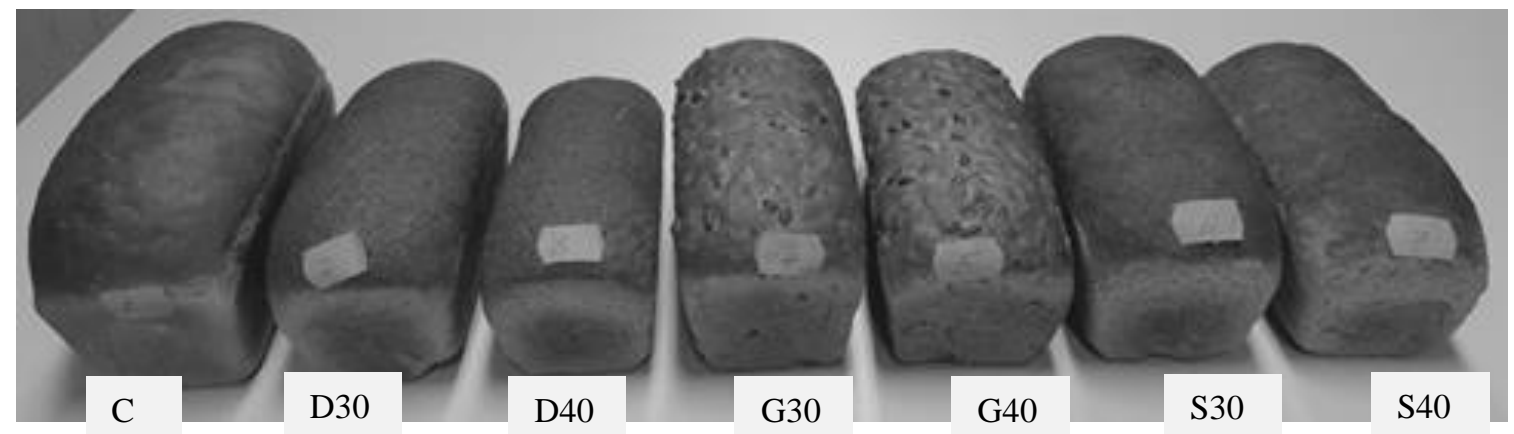

Figure 1. Samples of bread

C - 100\% wheat bread; D30 - 30\% naked barley flour; D40 - 40\% naked barley flour; G30 - 30\% naked barley grains; G40 - $40 \%$ naked barley grains; S30 - 30\% naked barley flour in sourdough; S40 - 40\% naked barley flour in sourdough

The negative changes of bread volume could be the result of an increased amount of dietary fibre and the presence of non-starch polysaccharides affecting gluten network weakening and lowering gas retention in the dough in consequence (Gänzle, 2014). Results of tested loaf volume, moisture and weight loss are summarised in the Table 3. Decrease in loaf volume in samples with higher barley content G40 versus G30 observed also when barley included as grains. The volume of bread samples with naked barley flours, grains and sourdough decreased compared to control (Figure 1). Bread samples with soaked naked barley grain on the crust were evident. The crust for bread samples with barley was not as smooth as the control sample. Al-Attabi et al. (2017) also found that crust sensory texture which was connected to the smoothness or roughness, decreased with the increasing substitution of barley flour or grain.

Table 3

Moisture, weight losses and loaf volume of fresh bread samples

\begin{tabular}{lccc}
\hline \multirow{2}{*}{ Samples } & Moisture, & Weight loss, & Loaf volume, \\
\cline { 2 - 4 } & $\boldsymbol{\%}$ & $\boldsymbol{\%}$ & $\mathbf{~ m L}$ \\
\hline C & $58.0 \pm 2.2$ & $11.3 \pm 0.6$ & $1178 \pm 22$ \\
D30 & $55.6 \pm 0.3$ & $10.3 \pm 0.4$ & $811 \pm 11$ \\
D40 & $55.6 \pm 0.2$ & $10.5 \pm 1.0$ & $711 \pm 9$ \\
G30 & $58.6 \pm 3.3$ & $9.8 \pm 0.9$ & $880 \pm 20$ \\
G40 & $55.9 \pm 0.2$ & $9.2 \pm 0.7$ & $781 \pm 20$ \\
S30 & $54.6 \pm 0.2$ & $10.2 \pm 0.1$ & $814 \pm 11$ \\
S40 & $55.2 \pm 0.3$ & $10.4 \pm 0.2$ & $764 \pm 30$ \\
\hline
\end{tabular}

C-100\% wheat bread; D30 - 30\% naked barley flour; D40 $40 \%$ naked barley flour; G30 - 30\% naked barley grains; G40 - 40\% naked barley grains; S30 - 30\% naked barley flour in sourdough; S40 - 40\% naked barley flour in sourdough

Comparing samples with the same barley content D40, G40 and S40 concluded that higher loaf volume determined if barley included in dough as grains. Using sourdough method (samples S30 and S40) contributed to higher volume of bread $814 \mathrm{~mL}$ and $764 \mathrm{~mL}$ respectively, than using direct method (loaf volumes $811 \pm 11 \mathrm{~mL}$ and $711 \pm 9 \mathrm{~mL}$ ). These results are in agreement with Pejcz et al. (2016) study where loaf volume using direct method was determined $530 \mathrm{~cm}^{3}$, but using sourdough method $557 \mathrm{~cm}^{3}$.
The results showed that moisture content was not influenced by amount of barley flour amount in dough, because in samples D30 and D40 determined the same moisture content, same as in bread samples S30 and S40 (Table 3). The smallest weight loss was determined in bread samples where included barley grains - G30, G40. This trend persistent in all storage time. Obtained results of moisture content (Figure 2) in storage time showed higher values in samples C, G30 and G40, it is in the wheat bread and in the bread with barley grains.

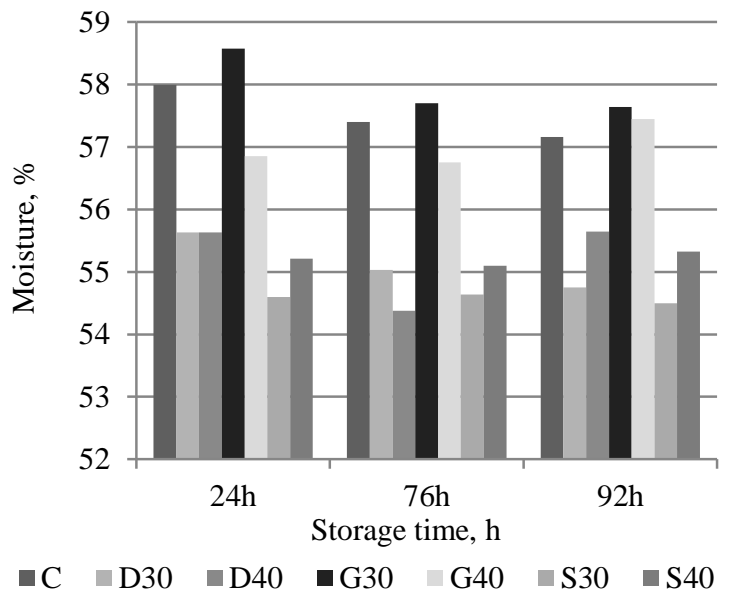

Figure 2. Changes of bread moisture during storage

C $-100 \%$ wheat bread; D30 - 30\% naked barley flour; D40 $40 \%$ naked barley flour; G30 - 30\% naked barley grains; G40 - 40\% naked barley grains; S30 - 30\% naked barley flour in sourdough; $\mathrm{S} 40-40 \%$ naked barley flour in sourdough

Grinding may affect the hydration properties, in particular, the kinetics of water uptake as the result of the increase of surface area, the fibres hydrate more rapidly (Dhingra et al., 2012). As it was observed comparing moisture content of the samples where used barley grains (D30, D49) and moisture content of the samples where used barley flour (D30, D40, S30, S40). The hardness increased within $96 \mathrm{~h}$ storage in all samples (Figure 3). The smallest increase calculated for samples $\mathrm{G} 30(4.0 \mathrm{~N})$ and $\mathrm{C}$ wheat bread $(4.5 \mathrm{~N})$ while in samples D30, D40, S30, S40 increase of hardness was similar $12.9 \mathrm{~N} ; 12.6 \mathrm{~N} ; 12.5 \mathrm{~N}$ and $13.5 \mathrm{~N}$ respectively. 


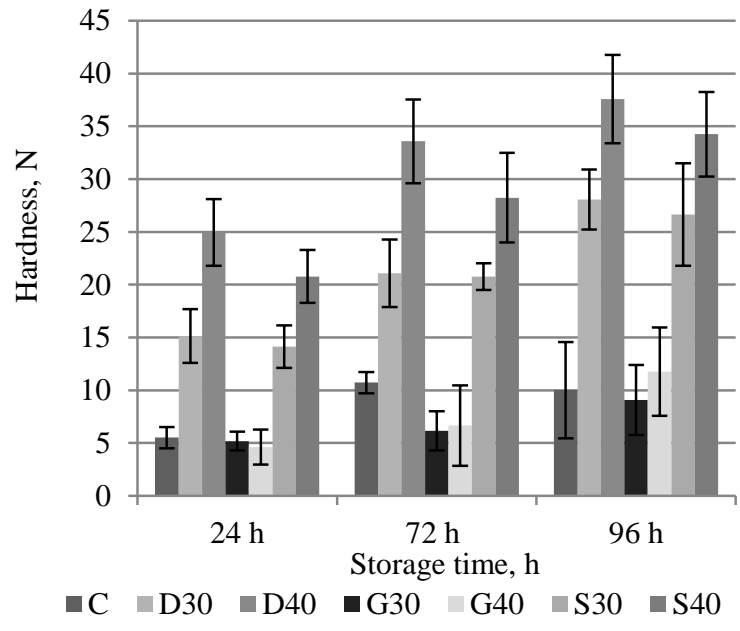

Figure 3. Hardness of bread samples in storage time C $-100 \%$ wheat bread; D30 - 30\% naked barley flour; D40 $40 \%$ naked barley flour; G30 - 30\% naked barley grains; G40 - 40\% naked barley grains; S30 - 30\% naked barley flour in sourdough; S40 - 40\% naked barley flour in sourdough

Results of hardness showed are similar for samples C, G30, G40. Hardness of samples with barley flour was significantly higher than hardness of samples with barley grains or wheat flour $(p<0.05)$. Comparison of samples with the same amount of barley flour showed advantages of sourdough method because hardness of samples D30 determined higher $(15.1 \pm 2.6 \mathrm{~N})$ than hardness of samples S30 $(14.1 \pm 2.0 \mathrm{~N})$ similar in samples with $40 \%$ barley flour content. Sheikholeslami et al. (2018) also concluded that effect of naked barley amount with guar gum on increasing the volume and decreasing the hardness of breadcrumb. The guar gum additive plays an important role here. With barley flour alone, it is difficult to reach a large volume of bread and good porosity.

Calculated nutritional value of bread samples assumed in Table 4.

\begin{tabular}{lccc} 
Nutrition value and energy value of bread samples \\
\hline \multirow{3}{*}{ Parameters } & \multicolumn{3}{c}{ Bread samples } \\
\cline { 2 - 4 } & C & D30; & D40; \\
& 218 & 212 & 210 \\
\hline Energy value, kcal & 923 & 898 & 889 \\
Energy value, kJ & 8.4 & 9.8 & 10 \\
Protein content, g 100 g & G40; S40 \\
Fat content, g 100 g-1 & 0.8 & 0.95 & 1.00 \\
Carbohydrates, g 100 g ${ }^{-1}$ & 43 & 39 & 38 \\
Dietary fibre, g 100 g-1 & 2.9 & 3.5 & 3.6 \\
- including $\beta$-glycans & 0.4 & 1.7 & 2.1 \\
\hline
\end{tabular}

$\mathrm{C}-100 \%$ wheat bread; D30 - 30\% naked barley flour; D40 $40 \%$ naked barley flour; G30 - 30\% naked barley grains; G40 - 40\% naked barley grains; S30 - 30\% naked barley flour in sourdough; S40 - 40\% naked barley flour in sourdough

Bread enriched with barley grains had significantly higher dietary fibre content including $\beta$-glycans content $(\mathrm{p}<0.05)$ and insignificantly higher protein and fat content $(p>0.05)$. Increase of barley content in flour composition results in decrease in carbohydrates content and total energy value.

\section{Sensory evaluation of bread}

Sensory evaluation results showed, that the addition of naked barley (flour, grains or sourdough) did not affect $(p=0.0513)$ the bread aroma intensity (Figure 4$)$. There were no significant differences $(p>0.05)$ in the intensity of bread crumb colour intensity between control (C) and bread with 30 and $40 \%$ barley grains (samples G30 and G40), but the crumb colour intensity influenced naked barley flour and sourdough - it became darker. Pejcz et al. (2017) reported, that a darker crumb colour of wheat bread with barley, influence consumers overall liking of bread samples. Kinner et al. (2011) found that addition of barley flour had a negative influence on bread volume and crumb texture.

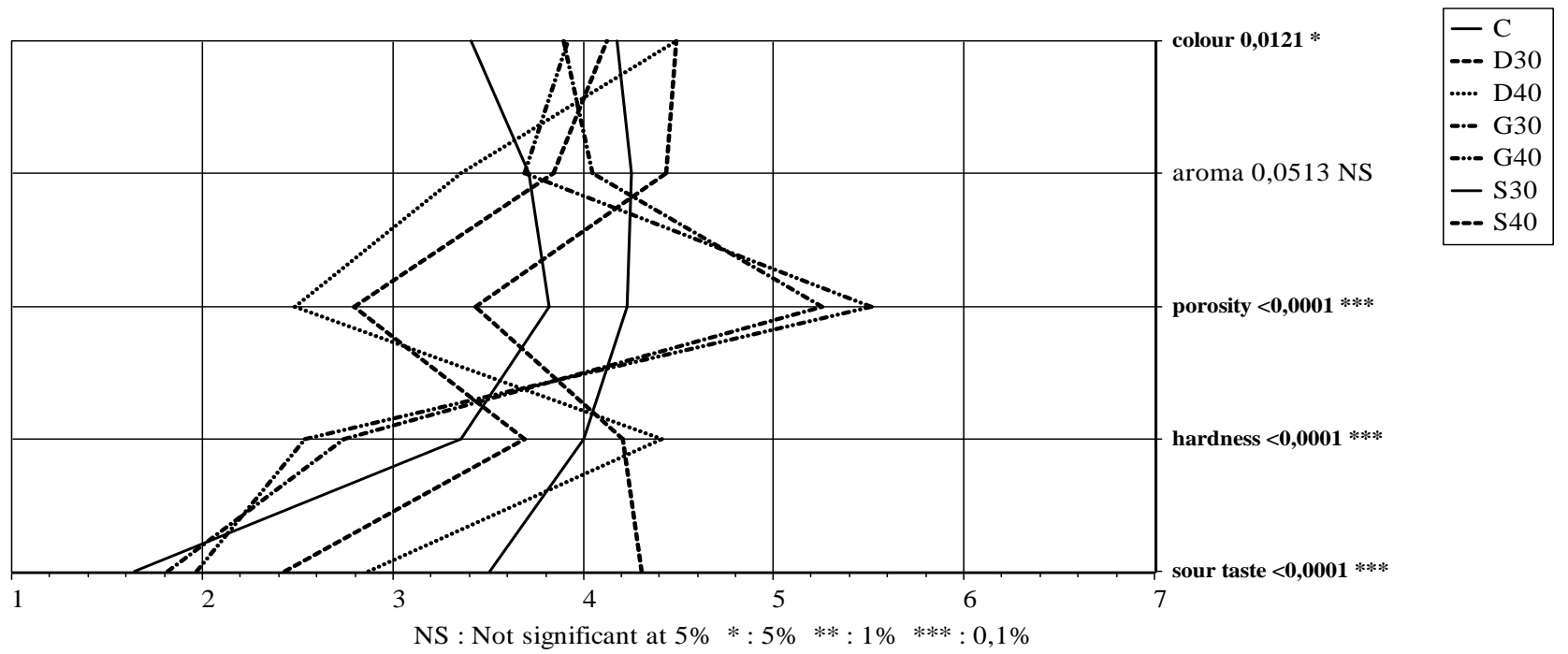

Figure 4. Sensory attributes intensity of bread with naked barley

C - 100\% wheat bread; D30 - 30\% naked barley flour; D40 - 40\% naked barley flour; G30 - 30\% naked barley grains; G40 - $40 \%$ naked barley grains; S30 - 30\% naked barley flour in sourdough; S40 - 40\% naked barley flour in sourdough 
Similar results have been obtained in our research samples D30 and D40 had less pronounced porosity. Though adding naked barley grains (30\% and $40 \%)$, it is possible to obtain bread with good porosity. In this study a strong negative correlation $(\mathrm{r}=-0.85)$ was found between bread porosity and hardness - bread has smaller pores in crumb, thus increasing the hardness of bread. The addition of sourdough from naked barley has a significant effect $(\mathrm{p}<0.05)$ on the sour taste of the analysed bread samples, resulting from the action of lactic acid bacteria of starter.

\section{Conclusions}

Bread enriched with barley grains has significantly higher content of dietary fibre, including $\beta$-glycans, higher protein and fat. Increase of barley content in flour composition results in decrease in carbohydrates and total energy value.

Results confirmed that high barley amount in dough led to decrease in loaf volume of bread - higher loaf volume of bread determined when barley included in dough as grains. Comparison of samples with same amount of barley flour showed advantages of sourdough method higher loaf volume and smaller hardness in storage time. Though adding naked barley grains to $30 \%$ and $40 \%$, it is possible to obtain bread with good porosity, but addition of sourdough increased the sour taste of bread.

\section{Acknowledgment}

The research was carried out at the laboratories of the Faculty of Food Technology of the Latvia University of Life Sciences and Technologies. The research was partly supported by project "The hull-less barley variety 'Kornelija' - high-quality wholegrain raw material for developing niche and functional products" (within the scope of Project Nr.KC-PI-2017/43)

\section{References}

1. Al-Attabi Z.H., Merghani T.M., Ali A., Rahman M.S. (2017) Effect of barley flour addition on the physicchemical properties of dough and structure of bread. Journal of Cereal Science, Vol. 75, p. 61-68.

2. Al-Saleh A., Brennan C.S. (2012) Bread wheat quality: some physical, chemical and rheological characteristics of Syrian and English bread wheat samples. Foods, Vol. 1, p. 3-17.

3. Arendt E.K., Zannini E. (2013) Barley. In: Cereal grains for the food and beverage industries. ed. S.Hughes. Cambridge: Woodhead Publishing. p. 155-200.

4. Arendt E. K., Ryan L. A., Dal B. F. (2007) Impact of sourdough on the texture of bread. Food Microbiology, Vol. 24(2), p. 165-174.

5. Baik B.K., Ullrich S.E. (2008) Barley for food: Characteristics, improvement, and renewed interest. Journal of Cereal Science, Vol. 48, p. 233-242.

6. Dhingra D., Michael M., Rajput H. Patil R.T. (2012) Dietary fibre in foods: A review. Journal of Food Science and Technology, Vol. 49 (3), p. 255-266.

7. Fulgoni V. L., Chu Y., O'Shea M., Slavin J. L.,
DiRienzo M. A. (2015) Oatmeal consumption is associated with better diet quality and lower body mass index in adults: the National Health and Nutrition Examination Survey (NHANES), 2001-2010, Nutrition Research, Vol. 35(12), p. 1052-1059.

8. Guler M. (2003) Barley grain beta-glucan content as affected by nitrogen and irrigation. Field Crops Research, Vol. 84, p. 335-340.

9. Gänzle M.G. (2014) Enzymatic and bacterial conversions during sourdough fermentation. Food Microbiology, Vol 37, p. 2-10.

10. Jacobs M.S., Izydorczyk M.S., Preston K.R., Dexter J.E. (2008) Evaluation of baking procedures for incorporation of barley roller milling fractions containing high levels of dietary fibre into bread. Journal of the Science of Food and Agriculture, Vol.88, p. 558-568.

11. Jenkins A.L., Jenkins D.J.A., Zdravkovic U., Wursch P., Vuksan V. (2002) Depression of the glycaemic index by high levels of beta-glucan fiber in two functional foods tested in type 2 diabetes. European Journal of Clinical Nutrition, Vol. 56, p. 622-628.

12. Kalra S., Jood S. (2000) Effect of dietary barley $\beta$-glucan on cholesterol and lipoprotein fractions in rats. Journal of Cereal Science, Vol. 31, 141-145.

13. Kinner M., Nitschko S., Sommeregger J., Petrasch A., Linsberger-Martin G., Grausgruber H. (2011) Naked barley optimized recipe for pure barley bread with sufficient beta-glucan according to the EFSA health claims. Journal of Cereal Science, Vol. 53(2), p. 225-230.

14. Meija L., Havensone G., Lejnieks A. (2019) Postprandial glycaemic and insulinaemic responses after consumption of activated wheat and triticale grain flakes. Journal of Nutrition and Metabolism, Vol. 2019, p. 1-7.

15. Pejcz E., Czaja A., Wojciechowicz-Budzisz A., Gil Z. (2017) The potential of naked barley sourdough to improve the quality and dietary fibre content of barley enriched wheat bread. Journal of Cereal Science, Vol. 77, p. $97-101$

16. Pejcz E., Wojciechowicz-Budzisz A., Gil Z., Czaja A., Radoslav S. (2016) Effect of naked barley enrichment on the quality and nutritional characteristic of read - Part I. The effect on wheat bread. Engeneering Sciences and Technologie, Vol. 2(21), p. 38-45.

17. Rieder A. Holtekjolen A.K., Sahlstrom S., Moldestad A., (2012) Effect of barley and oat flour types and sourdoughs on dough rheology and bread quality of composite wheat bread. Journal of Cereal Science, Vol. 55, p. 44-52.

18. Sheikholeslami Z., Karimi M., Komeili H. R., Mahfouzi M. (2018) A new mixed bread formula with improved physicochemical properties by using hull-less barley flour at the presence of guar gum and ascorbic acid. LWT-Food Science and Technology, Vol. 93, p. 628-633.

19. Skendi A., Biliaderis C. G., Papageorgiou M., Izydorczyk M.S., (2010) Effects of two barley $\beta$-glycan isolates on wheat flour dough and bread properties, Food Chemistry, Vol. 115, p. 1159-1167.

20. Sterna V., Zute S., Jansone I., Kantane I. (2017) Chemical composition of covered and naked spring barley varieties and their potential for food production. Polish Journal of Food and Nutrition Sciences, Vol. 67 (2), p. 151-158

21. Su X., Wu F., Zhang Y., Yang N., Chen F., Jun Z., Xu X. (2019) Effect of organic acids on bread quality improvement. Food Chemistry, Vol. 278, p. 267-275. 